www.jmscr.igmpublication.org

Impact Factor (SJIF): 6.379

Index Copernicus Value: 79.54

ISSN (e)-2347-176x ISSN (p) 2455-0450

crossrefDOI: https://dx.doi.org/10.18535/jmscr/v6i9.95

Journal Of Medical Science And Clinical Research

IGM Publication

An official Publication of IGM Publication

\title{
Study on Lipid Profile in Gestational Diabetic Patient and Normal Pregnant Women
}

\author{
Authors
}

\section{Dr Nasrin Rosy ${ }^{1^{*}}$, Dr Mohammad Monirul Islam ${ }^{2}$, Dr Munirunnessa ${ }^{3}$ Dr Khadija Mannan ${ }^{4}$, Dr Shamima Akhter ${ }^{5}$, Dr Shahinur Rahman ${ }^{6}$, Dr Lutfun Naher ${ }^{7}$,} Dr KBM Hadiuzzaman ${ }^{8}$

${ }^{1}$ Assistant Prof. Dept. of Obst. \& Gynae, Sir Salimullah Medical College, Dhaka

${ }^{2}$ Assistant Prof. Dept.of Neurosurgery, Faridpur Medical College, Faridpur

${ }^{3}$ Assistant Prof. Dept. of Obstetrics \& Gynaecology, Sir Salimullah Medical, College, Dhaka

${ }^{4}$ Junior Consultant (Obs \& Gynae) UHC, Muradnagar, Comilla

${ }^{5}$ Assistant Prof. Dept. of Obst. \& Gynae, Sir Salimullah Medical College, Dhaka

${ }^{6}$ Medical Officer, Sir Salimullah Medical College Mitford Hospital, Dhaka

${ }^{7}$ Assistant Prof. Dept.of Obst.and Gynae, Faridpur Medical College, Faridpur

${ }^{8}$ Associate Prof .Dept. of Nephrology, BSMMU, Dhaka

*Corresponding Author

Dr Nasrin Rosy

Assistant Prof. Dept. of Obst. \& Gynae, Sir Salimullah Medical College, Dhaka

Mobile-01715253207, Email: nasrin.rosy67@gmail.com

\begin{abstract}
Background: Gestational diabetes mellitus (GDM) is defined as any degree of glucose intolerance with onset or first recognition during pregnancy. Exposure of the fetus to maternal hyperglycemia can cause fetal malformations, as well as affecting fetal growth and glycemic regulation. GDM is also associated with considerable adverse outcomes for the mother and offspring in the short and long term.

Objective: The purpose of the study was to determine the changes in plasma lipids during pregnancy complicated by diabetes(Gestational diabetes mellitus) compared with non-diabetic pregnancy.

Methodology: This case control study was conducted in the department of Obstetrics and Gynaecology and outpatient department of BIRDEM and some selected private clinics from February 2016 to February 2017. A total 212 pregnant women were included in this study. The total number of subjects were divided into two groups. Group I consisted of 102 normal healthy pregnant women and 110 pregnant women who were diagnosed as GDM were listed in Group II. Gestational diabetes mellitus was diagnosed on the basis of a 2 sample OGTT (fasting and 2 hours after $75 \mathrm{~g}$ Oral glucose) following the WHO criteria as adapted in BIRDEM. Data were analyzed using statistical package for social science (SPSS) for windows version 20.

Results: Fasting plasma glucose levels and plasma glucose levels 2 hours after 75 gm oral glucose administration were significantly higher in patients with gestational diabetes as compared to controls $(5.70 \pm 1.5 \mathrm{vs} 3.98 \pm 0.61$ and $8.72 \pm 1.31$ vs $5.75 \pm 0.89$ ). Triglycerides level was increased significantly in gestational diabetes mellitus (GDM) group than normal healthy pregnant women $(210 \mathrm{vs} 188.5)$ respectively ( $P$ value 0.01$)$. There was also significant rise of LDL-Cholesterol level in GDM group compared with normal group (124.2 vs 114.0, P=0.042) But HDL-cholesterol was significantly lower in GDM women than normal healthy pregnant women (38.0 vs $41.0, P=0.026)$.

Conclusion: This study showed both triglycerides and LDL level were significantly elevated among women with GDM compared to those without GDM. On the otherhand HDL level decreased significantly in GDM subjects. These changes may have important implications for the development of atherosclerosis and long term cardiovascular health of women with diabetes.

Keywords: Gestational diabetes mellitus, Hyperlipidemia, Hemoglobin Alc.
\end{abstract}




\section{Introduction}

Gestational Diabetes Mellitus is "Carbohydrate intolerance of variable severity with the onset and first recognition during the present pregnancy" . It is a controversial clinical entity believed to be unmasking of a compensated metabolic abnormality characterized by relative insulin deficiency and increased insulin resistance. Moderate increase in blood glucose level particularly following ingestion of meal and changes in the levels of circulating free fatty acids, triglycerides, cholesterol and phospholipids. Diabetes is estimated to complicate $2-5 \%$ of all pregnancies of which $90 \%$ of those are detected during pregnancy i.e. Gestational Diabetes Mellitus and the rest are overt or pre-gestational i.e., Type 1 or Type 2 diabetes. ${ }^{1,2}$

Gestational diabetes is associated with adverse maternal and neonatal outcome. These adverse outcome include increased likelihood of abortion, preterm birth, cesarean delivery, macrosomia, congenital abnormalities, pre-eclampsia, and hypertension and complications of infants of diabetic mother. The frequency of congenital malformation is $6-10 \%$. Alteration in lipid profile is known to occur in gestational diabetes. Women with gestational diabetes have a significant risk of long-term morbidity and mortality due to cardiovascular disease (CVD), with heart disease being the leading cause of death ${ }^{3}$.This is a growing concern as women with GDM are increased risk of developing diabetes postpregnancy, in addition to hypertension, hyperlipidemia and coronary heart disease ${ }^{3-5}$.

Traditionally, gestational diabetes is considered as a disorder of carbohydrate metabolism; thus blood glucose levels have become the main key player for monitoring and directing treatment during pregnancy $^{3}$. This focus on glycemic metabolism ignores the important role of other potential fetal fuels such as proteins and lipid in the pathophysiology of GDM. ${ }^{4}$ This study is done to determine the changes of plasma lipids in pregnancy complicated by gestational diabetes and compare to normal pregnancies.

\section{Materials and methods}

This case control study was conducted in the Department of Obstetrics and Gynaecology and outpatient department of BIRDEM and some selected private clinics on the basis of availability. A total of 212 pregnant women were included in this study. The total number of subjects divided into two groups. Group I consisted of 102 normal healthy pregnant women and 110 pregnant women who were diagnosed as GDM were listed in Group II. Gestational diabetes mellitus was diagnosed on the basis of a 2 sample OGTT (fasting and 2 hours after $75 \mathrm{~g}$ Oral glucose) following the WHO criteria as adapted in BIRDEM. The subjects were informed and consent was taken. Subject were requested to overnight fast of at least 8-10 hours. About $10 \mathrm{cc}$ of blood were collected following all aseptic precaution from the ante-cubital vein using disposable plastic syringe. Anti coagulant was added for detection of HbA1c. Glucose level of the study subjects was measured by using Glucose Oxidase method (Randox, UK). Serum total cholesterol, triglycerides and HDL cholesterol were determined by enzymatic colorimetric methods using Randox Laboratories. LDLcholesterol was calculated according to Friedwald's formula. Data were analyzed using statistical package for social science (SPSS) for windows version 20 .

\section{Results}

Table 1: Clinical characteristics of the study subjects

\begin{tabular}{|l|c|c|c|}
\hline Variables & $\begin{array}{c}\text { Group I } \\
(\mathbf{n = 1 0 2})\end{array}$ & $\begin{array}{c}\text { Group II } \\
(\mathbf{n - 1 1 0})\end{array}$ & $\begin{array}{c}\text { P } \\
\text { value }\end{array}$ \\
\hline Average age (years) & $25.01(18-35)$ & $25.02(18-37)$ & 0.212 \\
\hline Gestational weeks & $26.5(10-34)$ & $27.0(10.34)$ & 0.810 \\
\hline Parity & $2.0(1-04)$ & $3.0(1-5)$ & 0.001 \\
\hline SBP (mm of Hg) & $106.67 \pm 9.98$ & $113.09 \pm 8.46$ & 0.001 \\
\hline DBP (mm of Hg) & $68.63 \pm 8.33$ & $73.89 \pm 7.27$ & 0.001 \\
\hline MBP (mm of Hg) & $81.31 \pm 5.98$ & $87.14 \pm 5.72$ & 0.001 \\
\hline
\end{tabular}

Group I: Consisted of 102 normal healthy pregnant women

Group II: Pregnant women who were diagnosed with GDM 
Table 2: Glycemic and insulinemic status of the study subjects

\begin{tabular}{|l|c|c|c|}
\hline Variables & $\begin{array}{c}\text { Group I } \\
(\mathbf{n = 1 0 2})\end{array}$ & $\begin{array}{c}\text { Group II } \\
(\mathbf{n = 1 1 0})\end{array}$ & $\begin{array}{c}\text { P } \\
\text { value }\end{array}$ \\
\hline $\begin{array}{l}\text { Fasting glucose } \\
(\mathrm{mmol} / \mathrm{l})\end{array}$ & $3.98 \pm 0.61$ & $5.70 \pm 1.5$ & 0.001 \\
\hline $\begin{array}{l}\text { Glucose after 2 } \\
\text { (mmol/1) }\end{array}$ & $5.75 \pm 0.89$ & $8.72 \pm 1.31$ & 0.001 \\
\hline HbA1c\%) & $5.25 \pm 0.43$ & $5.96 \pm 0.78$ & 0.001 \\
\hline HOMA\% B & $139.1(66.1-339.4)$ & $141.4(34.0-464.7)$ & 0.001 \\
\hline HOMA\%S & $124.5(49.03-299.5)$ & $64.3(25.7-90.5)$ & 0.001 \\
\hline
\end{tabular}

Group I: Consisted of 102 normal healthy pregnant women

Group II: Pregnant women who were diagnosed with GDM

Table 3: Lipidemic status of the study subjects

\begin{tabular}{|l|c|c|c|}
\hline Variables & $\begin{array}{c}\text { Group I } \\
(\mathbf{n = 1 0 2})\end{array}$ & $\begin{array}{c}\text { Group II } \\
(\mathbf{n}-110)\end{array}$ & P value \\
\hline TG $(\mathrm{mg} / \mathrm{dl})$ & $188.5(52.0-421.0)$ & $210.0(63.0-453.0)$ & 0.010 \\
\hline $\begin{array}{l}\text { Cholesterol } \\
(\mathrm{mg} / \mathrm{dl})\end{array}$ & $201.5(100.0-354.0)$ & $200.0(142.0-326.0)$ & 0.810 \\
\hline $\mathrm{HDL}(\mathrm{mg} / \mathrm{dl})$ & $41.0(23.0-73.0)$ & $38.0(19.0-69.0)$ & 0.026 \\
\hline $\mathrm{LDL}(\mathrm{mg} / \mathrm{dl})$ & $114.0(42.2-24.6)$ & $124.2(19.0-258.2)$ & 0.042 \\
\hline
\end{tabular}

Group I: Consisted of 102 normal healthy pregnant women

Group II: Pregnant women who were diagnosed with GDM

\section{Discussion}

Women with GDM are at high risk of maternal and fetal complications during pregnancy. Recent studies on experimental animals points towards an important role of intrauterine metabolic environment in the development of fetal malformation associated with GDM.,6 Disturbances of maternal metabolism are well known factors affecting the growth of fetus. Diabetes produces changes in maternal metabolic fuels and diabetic pregnancy is often associated with complications but the effects of maternal diabetes on lipid metabolism are unclear. ${ }^{7}$

The plasma lipids and lipoproteins changes in diabetic pregnancy have been studied by many researchers. $^{8,9,10}$ Women with GDM are significantly increased risk of developing metabolic dysfunction during pregnancy including hyperlipidaemia. ${ }^{10}$

The recent study was designed to observe the changes in lipid profile and glucose tolerance in normal health pregnancy (Group-I) and GDM subject (Group-II). In this study the glucose levels in GDM patients were significantly high $(\mathrm{p}<0.001)$ actual levels being $(5.7 \pm 1.5 \mathrm{mmol} / \mathrm{l})$ when compared to group-I $(3.98 \pm 0.61 \mathrm{mmol} / \mathrm{l})$. Similarly HbA1C a glycosylated hemoglobin fraction were done to know the previous 12 weeks glycemic status of the patients and poor glycemic control in diabetic patients have generally been found to have elevated serum lipid levels. ${ }^{11}$ In a study conducted by NR Kilby et al in $\mathrm{UK}^{12}$ found that $\mathrm{HbA} 1 \mathrm{C}$ was significantly greater in type-I diabetic mellitus than non-diabetic pregnancies being 9.6 percent and 6.8 percent respectively. Another study done by Ersanali et al. ${ }^{9}$ on GDM associated with fetal macrosomia showed significant higher values of $\mathrm{HbA1C}$ in GDM subjects when compared to non-diabetic control. Results of this study showed mean levels of HbA1C was $5.25 \pm 0.43$ in group-II which are significantly higher $(\mathrm{p}=0.001)$ than group-I (5.25 \pm 0.43$)$ These results are in accordance to other studies done on same subjects by Ersanali ${ }^{9}$ and Kilby. ${ }^{11}$

Hyperlipidemia is a common feature in normal pregnancy and consist primarily of tryglycerides with smaller rises in cholesterol. ${ }^{14}$ Total cholesterol level was studied in normal and GDM pregnancies by Sobki $^{14}$ and results reported showed a trend towards being higher in diabetic patients but no significant difference were encountered. In our study total serum cholesterol was elevated in group-II when compared to control group but the result is not significant. Regarding the triglycerides (T.G) women with GDM had higher level of triglycerides $(210 \mathrm{mg} / \mathrm{dl})$ than non-diabetic pregnancy $(188.5 \mathrm{mg} / \mathrm{dl})$ which showed a significant difference $(\mathrm{P}=0.010)$ These results are similar with all the studies consulted for lipidemia of pregnancy. ${ }^{, 8,13}$

LDL-cholesterol also elevates in pregnancy along with other lipids. A study done in by Mazukiewicz $^{15}$ depicts changes in LDLcholesterol where GDM patients failed to demonstrate significant a rise during pregnancy. Study results of Sobki ${ }^{14}$ showed non-significant rise of LDL in GDM patients when compared to 
normal pregnancy. Montelonge ${ }^{13}$ reported significant increase in LDL-cholesterol in GDM groups in comparison of normal pregnancies.

This study also showed significant rise in plasma LDL level in GDM women compared to control group (124.2 vs $114.0, \mathrm{P}=0.042)$.This result did not agree with the results of Hollingsworth and Grundy ${ }^{16}$ where no significant difference was found in LDL values in GDM and normal pregnancy.

There is some evidence that not only TG and cholesterol are elevated but also the concentration of HDL-cholesterol is decreased in pregnant women. Hollingsworth studied HDL-cholesterol in GDM and values were found lower than normal pregnancy status. The result of this study also showed significantly lower $(\mathrm{P}<0.001)$ values of HDL in GDM group than normal pregnancy. Actual values being (41.0) and (38.0) in group-I and group-II respectively. From the above results it seems that diabetic subjects have lower HDLcholesterol values which do not increase even under the influence of pregnancy induced hyperlipidemia.

\section{Conclusion}

This study conclusively shows that triglycerides and LDL level are significantly elevated during pregnancy in women with GDM compared to normal pregnant women. On the other hand HDLCholesterol level is markedly reduced in patients, which do not increase even under pregnancy induced hyperlipidemia. Estimation of lipid profile during pregnancy is strongly recommended as part of laboratory investigation so as to instill prompt management strategies to prevent deleterious effects of hyperlipidemia associated with pregnancy. Additionally, more research is needed to explore the role of dyslipidemia in pathogenesis of GDM and potential methods for treating GDM in women with elevated triglycerides during pregnancy.

\section{References}

1. Suresh E, Prasad GBVVSV. Study of biochemical changes in gestational diabetes mellitus. International Journal of Applied Research 2017; 3(8): 03-08

2. American Diabetes Association. Diagnosis and classification of diabetes mellitus. Diabetes care. 2009;32:62-7.

3. Khan R, Ali K, Khan Z, Ahmad T. Lipid profile and glycosylated hemoglobin status of gestational diabetic patient and healthy pregnant women. Indian Journal of Medical Science 2012;66(7):149-154.

4. Chen $\mathrm{L}, \mathrm{Hu} \mathrm{FB}$, Yeung E, Willett W, Zhang C. A prospective study of pregravid sugar sweetened beverage consumption and the risk of gestational diabetes mellitus. Diabetes Care 2009;32:2236-41.

5. Damassceno DCVG. Oxidative stress and diabetes in pregnant rats. Anim Repro Sci. 2002; (72), 235.

6. Knopp RHVM.. Effect of insulin dependent diabetes on plasma lipoproteins in diabetic pregnancy. $\mathbf{J}$ Reprod Med 2013;(3809), 703-10.

7. Schaefer-Graf. Birth weight and parental BMI predict overweight in children from mothers with gestational diabetes. Diabetes Care 2005; (28):1745-50.

8. Schaefer-Graf. Maternal lipids a strong determinants of fetal environment and growth in pregnancies with gestational diabetes mellitus. Diabetic Care 2008; (31):1858-63.

9. Ersanali ZO. Lipid metabolism alteration in patients with gestational diabetes mellitus associated fetal macrosomnia. Ann Ist Super Sanita 1997;33(3):411.

10. WB K. Lipids, diabetes and coronary heart disease: Insight from the framingham study. Am Heart J 2015;(110): 1100-06.

11. Kilby NR. Fetal and maternal lipoprotein metabolism in human pregnancy complicated by type I diabetes mellitus. J 
Clin Endocrinal Metab 2008; (83 (5), 1736-41.

12. Merzouk HBM. Fectal macrosonia related to maternal poorly controlled type I diabetes strongly impairs lipoprotein concentration and composition. J Clin Pathol 2000;(53):917-23.

13. Montelonge ALM. Longitudinal study of plasma lipoproteins and hhormones during pregnancy in normal and diabetic women $\mathrm{J}$ Clin Endocrinal Metab 2002;(41):1651-59.

14. Sobki SH. Impact of estational diabetes on lipids profiling and indices of oxidative stress in maternal and cord plasma. Saudi Med J 2004;25 (7):876.

15. Mazurkiewicz JCWG. Serum lipids, lipoprotein and apalipoproteins in pregnant non-diabetic pateints. J Clin Pathol 2014;(47):728-31.

16. Hollingworth DR. and Grundy SM: Pregnancy associated hypertriglyceridemia in normal and diabetic women: Differences in insulin-dependent, non insulin-dependent and gestational diabetes. Diabetes.1982 Dec,31(12):1092-7. 